\title{
Pemphigoid Gestationis: A Rare Dermatosis of Pregnancy
}

\author{
Victoria Tran, MS3 \\ Thomas Jefferson University, victoria.tran@jefferson.edu \\ Meghan Belamorich, MD \\ Thomas Jefferson University, meghan.belamorich@jefferson.edu
}

Follow this and additional works at: https://jdc.jefferson.edu/tmf

Part of the Dermatology Commons, and the Internal Medicine Commons

Let us know how access to this document benefits you

\section{Recommended Citation}

Tran, MS3, Victoria and Belamorich, MD, Meghan (2016) "Pemphigoid Gestationis: A Rare Dermatosis of Pregnancy," The Medicine Forum: Vol. 17, Article 19.

DOI: https://doi.org/10.29046/TMF.017.1.020

Available at: https://jdc.jefferson.edu/tmf/vol17/iss1/19

This Article is brought to you for free and open access by the Jefferson Digital Commons. The Jefferson Digital Commons is a service of Thomas Jefferson University's Center for Teaching and Learning (CTL). The Commons is a showcase for Jefferson books and journals, peer-reviewed scholarly publications, unique historical collections from the University archives, and teaching tools. The Jefferson Digital Commons allows researchers and interested readers anywhere in the world to learn about and keep up to date with Jefferson scholarship. This article has been accepted for inclusion in The Medicine Forum by an authorized administrator of the Jefferson Digital Commons. For more information, please contact: JeffersonDigitalCommons@jefferson.edu. 


\section{Pemphigoid Gestationis: A Rare Dermatosis of Pregnancy}

Victoria Tran, MS3 and Meghan Belamorich, MD

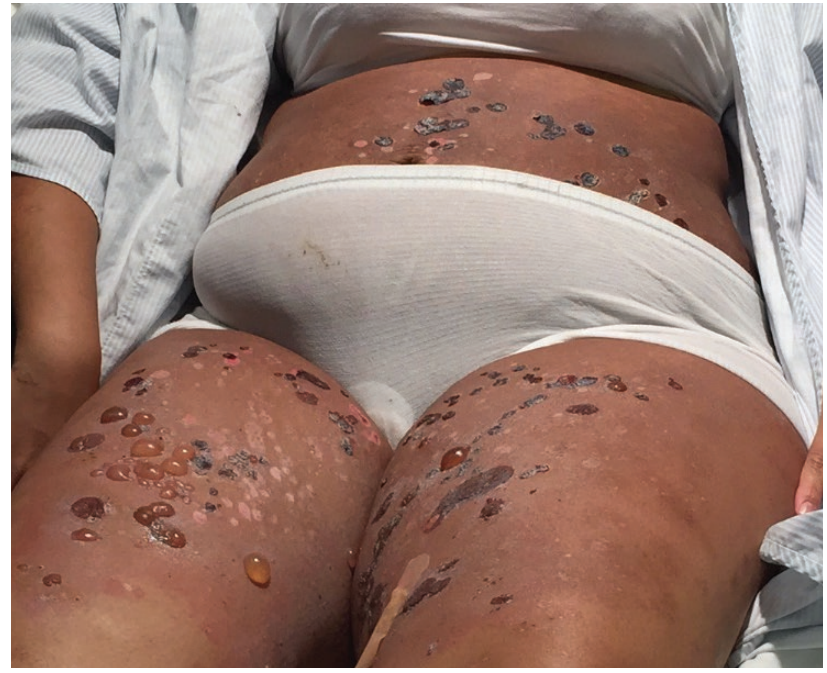

Figure 1. Bullae at various stages of healing on the abdomen, and medial and anterior thighs.

\section{INTRODUCTION}

Pemphigoid gestationis is a rare dermatosis of pregnancy that often goes unrecognized or misdiagnosed. It can lead to adverse fetal outcomes including preterm delivery, low fetal birth weight, and even neonatal pemphigoid gestationis ${ }^{1}$. As such, proper diagnosis and management is critical in reducing fetal risk.

\section{CASE PRESENTATION}

A 23 year-old Hispanic G4P2103 woman at 36 weeks and 5 days of gestation presented to the emergency department with a bullous rash associated with pruritus and erythema of 1 month duration. The rash started with a few small pruritic and painful vesicles around her umbilicus that spread to the rest of her abdomen, legs, and arms and coalesced to become bullae (Figures 1,2). Her chest and back had a pruritic, erythematous rash without bullae (Figure 3), but her fatce, hands, feet, and oral mucosa were spared.

The patient was initially diagnosed with herpes by her outpatient provider and was prescribed valacyclovir, but noted no improvement in her symptoms. Subsequently, she was thought to have a bullous disease and given a methylprednisolone dose pack. While the patient subjectively claimed to feel better, her lesions continued to progress. She was then referred to an allergist who told her to go to the emergency department.

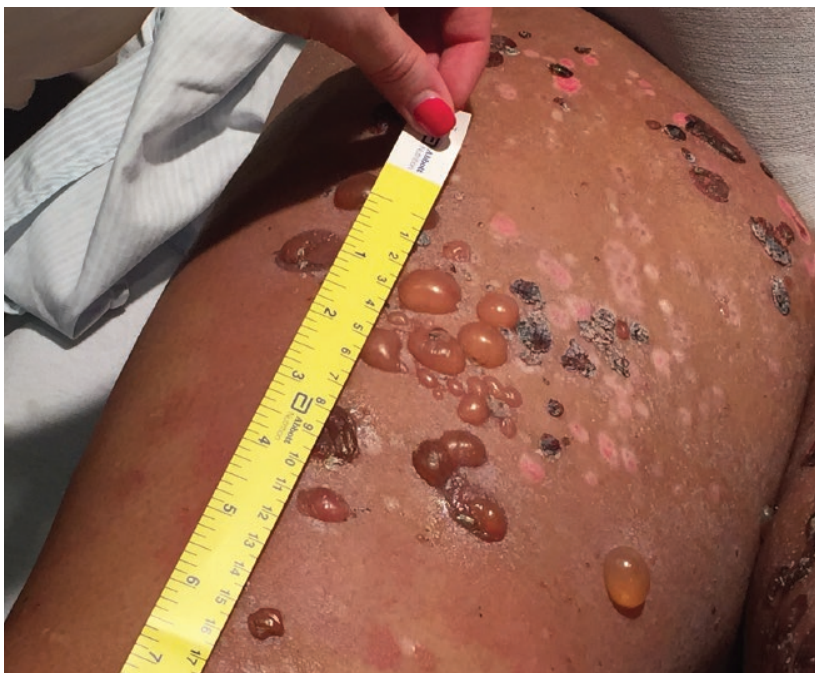

Figure 2. Right thigh. Various stages of healing

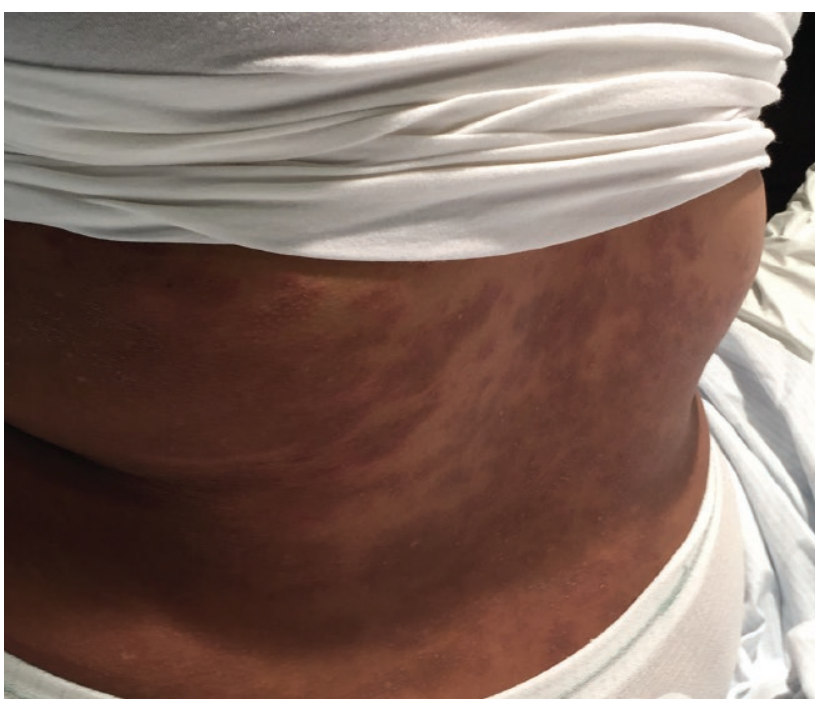

Figure 3. Back rash without bullae

The patient was otherwise healthy and denied a personal and family history of autoimmune or dermatologic conditions, a history of drug allergies, recent environmental exposures, new medications, insect bites, sick contacts, and travel. No rash was noted with any of her previous three pregnancies. 


\section{The Medicine Forum, Vol. 17 [2016], Art. 19}

\section{OUTCOME AND FOLLOW-UP}

After consultation with internal medicine and dermatology, the patient was diagnosed with pemphigoid gestationis based on history and clinical presentation and started on topical clobetasol to intact lesions and oral prednisone $40 \mathrm{mg}$ daily to be tapered once lesions crust over.

During the remainder of her pregnancy, the patient developed edema and hypertension and labor was induced. Fortunately, there were no further complications with her delivery and the infant was born healthy without any detectable lesions. Figures 1-3 show the patient's lesions in various stages of healing, one day after delivery.

\section{DISCUSSION}

Pemphigoid gestationis is a rare autoimmune dermatosis of pregnancy that affects approximately 1 in 50,000 pregnant women in the United States ${ }^{2}$. While its exact pathogenesis is not known, it has been postulated to result from maternal IgG autoantibodies induced by the paternal major histocompatibility complex class II antigens in the placenta, the most common being DR-3 and DR-4. The pathologic antibodies cross the placenta and cross-react with proteins in the maternal skin, leading to an inflammatory response that ultimately results in the formation of bullae ${ }^{3.4}$. Some studies suggest that estrogen and progesterone may also play a role in disease pathogenesis, as flare-ups have been demonstrated immediately post-partum, during menstruation, and with oral contraceptive use ${ }^{3}$

Pemphigoid gestationis typically occurs in the second or third trimester and initially presents with intensely pruritic, erythematous papules or plaques around the umbilicus that spreads to the abdomen, back, chest, and extremities and eventually form bullae ${ }^{5}$. Occasionally, as demonstrated in this case, vesicles are present initially. In many cases, lesions can extend to the soles and palms, but involvement of the face and mucosal surfaces is rare. A detailed history along with laboratory evaluation which include immunoflourescence and histopathology of skin lesions would help in coming to a precise diagnosis.

Treatment of this condition is largely symptomatic. The current standard of care is topical corticosteroids for localized lesions and systemic corticosteroids if the topical formulations do not control symptoms. Few case reports have suggested intravenous immunoglobulin may be an acceptable treatment option if corticosteroids cannot be tolerated ${ }^{6}$. Because this condition is associated with an increased incidence in preterm delivery and low birth-weight neonates, it is important that these patients deliver in facilities that have a neonatal intensive care unit and that are prepared to deal with these complications ${ }^{6}$.

Because pemphigoid gestationis is uncommon in the United States, it can often be missed or misdiagnosed and patients may be sent from specialist to specialist, like the patient in this case. It is important to be able to recognize this dermatosis to reduce the risk of neonatal complications and for appropriate management of the neonate.

\section{REFERENCES}

1. Sadie Henry. Recognizing Presentations of Pemphigoid Gestationis: A Case Study. Case Reports in Obstetrics and Gynecology. 2014; 2014: 415163.

2. Kanwar AJ. Pemphigoid gestationis. British Journal of Dermatology. 2015; 172: 6-7

3. Argueta EE, Tschen JA. What is your diagnosis? pemphigoid gestationis (herpes gestationis). Excerpta Medica. 2015; 95(5): 268, 270

4. Senturk Senol, Dilek Nursel, Tekin YB, et al. Pemphigoid Gestationis in a Third Trimester Pregnancy. Case Reports in Obstetrics and Gynecology. 2014; 2014: 127628

5. Nguyen T, Alraqum E, Razzaque Ahmed A. Positive clinical outcome with IVlg as monotherapy in recurrent pemphigoid gestationis. International Immunopharmacology. 2015; 26(1): 1-3.

6. Holmes RC, Black MM. The fetal prognosis of pemphigoid gestationis (herpes gestationis). British Journal of Dermatology. 1984; 110(1): 67-72 